\title{
Experimental Investigation on Effect of Carbon Nanotubes and Carbon Fibres on the Behavior of Plain Cement Mortar Composite Round Bars under Direct Tension
}

\author{
A. M. Hunashyal, ${ }^{1}$ Sagar V. Tippa, ${ }^{1}$ S. S. Quadri, ${ }^{1}$ and N. R. Banapurmath ${ }^{2}$ \\ ${ }^{1}$ Department of Civil Engineering, B.V.B. College of Engineering and Technology, Hubli-580031, Karnataka, India \\ ${ }^{2}$ Department of Mechanical Engineering, B.V.B. College of Engineering and Technology, Hubli-580031, Karnataka, India
}

Correspondence should be addressed to N. R. Banapurmath,nr_banapurmath@rediffmail.com

Received 4 June 2011; Accepted 12 July 2011

Academic Editor: D. K. Sarker

Copyright (C 2011 A. M. Hunashyal et al. This is an open access article distributed under the Creative Commons Attribution License, which permits unrestricted use, distribution, and reproduction in any medium, provided the original work is properly cited.

\begin{abstract}
This paper investigates the behavior of reinforced cement mortar composite round bars with multiwalled carbon nanotubes (MWCNTs) and carbon fibers (CFs). The percentage of CFs was fixed at $2.25 \mathrm{wt} \%$ of cement, while the percentage of MWCNTs was fixed at 0.5 , by wt $\%$ of cement. Dispersion of both MWCNTs and CFs was carried out using ultrasonic energy method. Composite round bars were tested under direct tension in order to evaluate their mechanical properties such as ultimate load, deflection criteria, and stress-strain behavior. These results were then compared with the results of plain cement control round bars. From the study, it is shown that the load carrying capacity of composite bars under direct tension is substantially higher than the plain controlled bar.
\end{abstract}

\section{Introduction}

Although concrete is not normally designed to resist direct tension, the knowledge of tensile strength of concrete is of value in estimating the load under which cracking will develop [1]. A direct application of pure tension and avoiding secondary stresses during testing of the specimen is difficult. Advanced technological aspects demand for higher performing cement-based materials with improved tensile strength and toughness for use in civil engineering projects. Cementitious materials are typically characterized as quasibrittle materials, with low tensile strength and low strain capacity, and hence affect long-term durability of structures. These days, discrete short fibers are widely used to control cracking in fiber-reinforced concrete (FRC) [2]. Nanotechnology is one of the most active researched areas, with both novel science and useful applications, that has gradually established itself in the past two decades $[3,4]$.

Nanoscience has a central role to play, in producing innovative concrete materials for the 21st century. It enables scientists to work at the molecular level atom by atom to develop new materials fundamentally with new physical and chemical properties [5]. Hydrated cement is porous with a pore size distribution that ranges from the nanometers to millimeters. The dimensional range of solids and pores in a hydrated cement paste has been reported in the literature [1]. Carbon nanotubes (CNTs) are the subject of one of the most important areas of research [6]. The incorporation of MWCNTs in cement increases the amount of stiffness of C$\mathrm{S}-\mathrm{H}$ gel resulting in stronger material. Carbon nanotubes (CNTs) were discovered in 1991 by Iijima in Japan [7]. CNTs are classified as either single walled carbon nanotubes (SWCNTs) or multiwalled carbon nanotubes (MWCNTs). CNTs are found to possess a Young's modulus of $1 \mathrm{TPa}$, a yield stress of 100-300 GPa [2], and a tensile strength of $63 \mathrm{GPa}[6,8]$. The present paper utilizes MWCNTs, having diameters of $10-30 \mathrm{~nm}$, densities $1000-2000 \mathrm{~kg} / \mathrm{m}^{3}$, and an aspect ratio of 1000. Both micro- and nanolevel reinforcements were provided to study the effect on the overall properties of the composite.

While the exploration for various applications of nanotechnology to develop innovative construction materials continues, it is already clear that the science of the very small is making big changes, with numerous economic benefits for 
TABLE 1: Properties of MWCNTs and carbon fibers used herein.

\begin{tabular}{lc}
\hline \multicolumn{2}{c}{ MWCNTs as supplied by Intelligent Private Limited } \\
\hline Diameter & $10-30 \mathrm{~nm}$ \\
Length & $1-2$ microns \\
Purity & $>95 \%$ \\
Surface area & $350 \mathrm{~m}^{2} / \mathrm{g}$ \\
Bulk density & $0.05-0.17 \mathrm{~g} / \mathrm{cm}^{3}$ \\
\hline \multicolumn{1}{c}{ Carbon fibers as supplied by Fosroc-Chemicals, Bangalore } \\
\hline Density & $1.8 \mathrm{~g} / \mathrm{cc}$ \\
Tensile strength & $3500 \mathrm{~N} / \mathrm{mm}^{2}$ \\
Length of fiber & $5 \mathrm{~mm}$ \\
Fiber thickness & $0.3 \mathrm{~mm}$ \\
\hline
\end{tabular}

the construction industry [9]. By using carbon nanotubes, a new material which exhibits enhanced tensile strength, young's modulus and improved early a strain capacity can be created as found in the literature [10]. However, two problems with the addition of carbon nanotubes and carbon fibers to any material are the clumping together of the tubes, fibers and the lack of cohesion between them and matrix bulk material. A uniform dispersion must be achieved to get the desired results. The cost of adding CNTs to concrete may be prohibitive at the moment, but work is being done to reduce their price and at such time the benefits offered by their addition to cementitious materials may become more palatable.

Experimental works carried out by [2] showed that by adding $0.25 \mathrm{wt} \%$ of cement MWCNTs to the plain cement beams, one may get a remarkable enhancement in both flexural strength and toughness. In comparison with plain cement beams, the CNT reinforced beams showed $47 \%$ increase in the load carrying capacity and an average of $25 \%$ increase in the toughness. CNT/cement composites under flexure with $0.08 \mathrm{wt} \%$ of cement MWCNTs with proper dispersion was tested, and it was found that fracture properties of cement matrices can be substantially increased by adding a very low amount of CNTs (e.g., $0.025 \mathrm{wt} \%$ to $0.10 \mathrm{wt} \%$ of cement). Scanning Electron Microscopy results showed that the addition of a small amount of CNTs enables the control of matrix cracks at the nanoscale level. The nanoindentation results suggested that CNTs can modify and reinforce the cement paste matrix at the nanoscale. The foregoing results suggest that CNTs have potential for being used as reinforcement for concrete; however, there is still a significant need for further research studies in this area to completely understand the structural behavior of CNTreinforced cement $[11,12]$.

Fundamentally, hydrated cement paste (HCP) is a nanomaterial. Knowledge at the nanoscale level of the composition and characteristics of materials will promote the exploration of new applications and new products which can be used to repair or to improve the properties of construction materials [11]. The performance of concrete can also be improved by adding nanotubes. The compression strength of the cement paste increased with the addition of
CNTs that decrease the number of mesopores as reported in earlier studies [13]. Carbon nanotubes have the potential to enhance the strength, effectively hinder crack propagation in cement composites, and act as nucleating agents [4]. Reinforcing concrete with nanofibres will produce tougher concretes by interrupting crack formation as soon as it is initiated. The carbon nanofibres interactions in cement matrix that hinder crack propagation are reported in the literature [5].

Carbon Fibers. They are used in conventional fiberreinforced concrete and were found to be ideal reinforcing materials. They have established themselves as a suitable material for retrofitting and strengthening purpose. Recently, in the field of fiber reinforced concrete, there has been much enthusiasm for the development of hybrid fiber systems where two or more types of fibers are combined [14, 15]. Hybrid fiber systems are a promising approach for making efficient use of fibers with the intent of conferring the best performance characteristics of each of the constituent fiber $[16,17]$. Recent work at Advance Cement Based Material Research Centre (ACBM) has shown that fiber hybridization effectively enhances the material performance. The mechanical properties of cementations composites were improved by using fibers of varying sizes and moduli. The addition of small amounts of less than 1\%wt of CNTs can improve the mechanical properties of samples consisting of main Portland cement paste and water. Oxidized MWCNTs show the best improvements both in compressive and flexural strength as compared to the reference samples without the fiber reinforcement $[3,12]$. The research work carried out on use of carbon fibers and CNTs in beams has reported that both CF and CNTs act as good reinforcing materials and strengthen the composite beams both at macro- and microlevels in cement-based composite beams [18].

\section{Experimental Programme}

Experimental tests were conducted to investigate the effect of dispersed and randomly oriented micro- (MWCNTs) and macro- (CFs) level reinforcement in cement mortar round bars. Preliminary tests on cement mortar were conducted as per IS:4031 Bureau of Indian standards. Direct tension test was carried out on round composite cement mortar bars. The properties of MWCNTs and CFs used in the study are given in Table 1. MWCNTs used in this study were of industrial grade with a purity of greater than $95 \%$. A water cement ratio (w/c) of 0.4 was found to be appropriate in terms of mixing and workability of the paste after adding the fibers. The details of the mix proportion, size of the specimens, and the percentage of carbon fibers and multiwalled-carbon nanotubes used are given in Table 2. Test specimens used were designated accordingly and their details are given in Table 3. Table 5 shows the specifications of the tensile testing machine.

2.1. Dispersion Technique and Preparation of the Specimen. Dispersion is a critical issue while mixing CNTs in either 
TABLE 2: Specimen characteristics of mix proportion used $1: 1$.

Length of the specimens

Diameter of the specimens

Water cement ratio

Percentage of carbon fibers (CFs) used

Percentage of Multiwalled Carbon

Nanotubes (MWCNTs) used
$500 \mathrm{~mm}$

$30 \mathrm{~mm}$

0.40

$2.25 \%$ by the weight of the cement.

$0.5 \%$ by the weight of the cement.

TABLe 3: Specimen reference.

\begin{tabular}{lcccc}
\hline S. no. & $\begin{array}{c}\text { Specimen } \\
\text { reference }\end{array}$ & Constituents & $\begin{array}{c}\text { Specimen details } \\
\text { Percentage of carbon fiber } \\
(5 \text { mm length) }\end{array}$ & Percentage of MWCNTs \\
\hline 1 & PB & Plain Cement mortar Bar & Nil & Nil \\
2 & A & Plain Cement mortar Bar + Carbon Fibers (CF) & $2.25 \%$ & Nil \\
3 & B & Plain Cement mortar Bar + MWCNT & Nil & $0.50 \%$ \\
4 & C & Plain Cement Mortar bar + CF + MWCNT & $2.25 \%$ & $0.5 \%$ \\
\hline
\end{tabular}

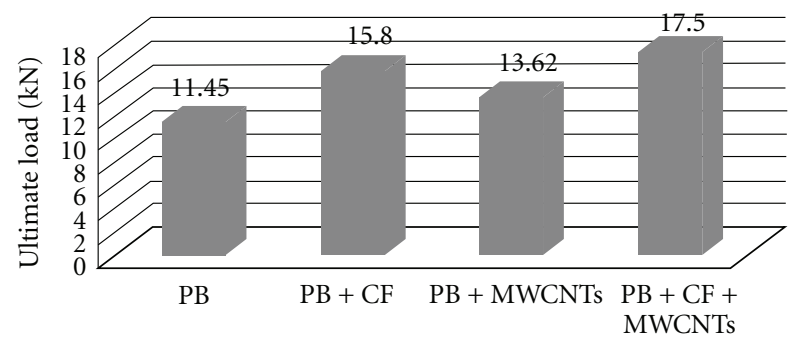

Figure 1: Ultimate load of composite bars subjected under direct tensile load.

water or organic solvents. Uniform dispersion of MWCNTs against their agglomeration due to van der Waals bonding is the first step in the processing of nanocomposites. Proper dispersion and adequate load transfer are the main challenges in the search for efficient carbonfibres/carbon nanotubes-reinforced cement composites $[19,20]$. First the MWCNTs were predispersed in acetone by means of an ultrasonic probe (Vibration by ultrasound) of capacity $2800 \mathrm{~kJ} / \mathrm{I}$. After four hours, the sonication was stopped and the acetone was allowed to evaporate [21]. Next carbon fibres were predispersed in water by adding 3/5th of the water required for mixing of cement; sonication was carried for 10 minutes. Next dispersant Hydroxyethyl cellulose (HEC) of quantity $0.06 \%$ by weight of cement was added to the predispersed mixture and again sonicated for about 10 minutes with continuous stirring. Addition of HEC converts fibers into sticky paste, and thus bundled carbon fibers get dispersed. The CNTs are than added into aqueoussurfactant solution. Based on previous research [22], a constant surfactant to MWCNTs weight ratio of 4 was found to achieve effective dispersion. Further the cement paste composites along with carbon fibers are mixed with sonicated suspension (dispersion). Mixing of the material was performed according to the procedure outlined by the ASTM 305 using a standard Hobart mixer. After mixing, the paste was cast in a mould that is designed in the form of a half cell openable as shown in Figure 4. The samples were than maintained for $24 \mathrm{hrs}$ in water vapour saturated atmosphere. Subsequently, they were demoulded and put for 27 days at $20^{\circ} \mathrm{C}$, until tests, leading to total curing time of 28 days.

\section{Results and Discussion}

Tensile test was carried out on the specimens in the UTM. Ultimate load and maximum deformation were noted down for each specimen; and the average of the three specimens tested was taken for the analysis. Table 5 gives the average ultimate tensile strength of Plain bars [PB], Carbon-fiber reinforced bars $[\mathrm{A}]$, and MWCNT-reinforced bars [B]. Figure 1 shows a graphical representation of average direct tensile strength for Plain cement mortar bars (PBs), bars with randomly distributed carbon fibers $(2.25 \%)(\mathrm{A})$, bars with randomly distributed multiwalled carbon nanotubes $(0.5 \%)$, (B) bars with randomly distributed carbon fibers $(2.25 \%)$, and multiwalled carbon nanotubes (0.5\%) (C). From Figure 1, it is observed that there is an increase in the tensile strength of bars with composite materials compared to plain bars. It indicates that presence of composite materials in bars plays a major role in increasing tensile strength. Strong interfacial bonding between the composite materials and the matrix caused efficient stress transfer when strain is applied on a tensile specimen. It is seen that bars with random distribution of carbon fibers, that is, $2.25 \%$ by the weight of cement increase the tensile strength by $38 \%$ compared to plain bars. Bars with random distribution of carbon fibers $(2.25 \%)$ and random distribution of multi walled carbon nanotubes, that is, $0.5 \%$ by the weight of cement increase the tensile strength by $53.28 \%$ compared to plain bars.Bars with random distribution of multiwalled carbon nanotubes, that is, $0.5 \%$ by the weight of cement, increase tensile strength by $19 \%$. 
TABLE 4: Test results for MWCNT + CF reinforced cement composite Bar.

\begin{tabular}{llcc}
\hline S. no. & Specimen reference & $\begin{array}{c}\text { Ultimate tensile } \\
\text { load (in kN) }\end{array}$ & $\begin{array}{c}\text { Maximum } \\
\text { deflection (in mm) }\end{array}$ \\
\hline 1 & Plain Bars (PBs) & 11.45 & 3.32 \\
2 & Plain Bar + 2.25\% of carbon fibers (A) & 15.8 & 5.5 \\
3 & Plain Bar + 0.5\% MWCNT (B) & 13.65 & 4.25 \\
4 & + Plain Bar + 2.25\% of carbon fibers + 0.5\% MWCNT (C) & 17.55 & 5.92 \\
\hline
\end{tabular}

TABLE 5: Specifications of the tensile testing machine.

\begin{tabular}{lcc}
\hline S. no. & Particulars & $500 \mathrm{~mm}$ \\
\hline 1 & Maximum capacity & $10 \mathrm{kN}$ \\
2 & Minimum graduation & $10 \mathrm{~N}$ \\
3 & Make & Fine testing machine, Miraj \\
\hline
\end{tabular}

Stress-Strain Curves. Figure 2 shows the stress-strain curve for the various specimens tested. It is known that even under short-term loading, concrete does not behave as an elastic material. However, up to about $10-15 \%$ of the ultimate strength of concrete, the stress strain graph is not very much curved and hence can give more accurate value. The stress strain relationship of concrete which is a combination of aggregate and paste together shows a curved relationship. Perhaps this is due to the development of microcracks at the interface of the aggregate and paste. Because the failure of bond at the interface increases at a faster rate than that of the applied stress, the stress strain curve continues to bend faster with increase of stress.

Figure 2 shows the variation of stress strain diagram for various composite bars under direct tensile load. On the contrary, the stronger the concrete, the higher the modules of elasticity. This can be explained that the stronger is the concrete, the stronger is the gel and hence the less is the strain for a given load. Because of lower strain, the modulus of elasticity is higher.

It is noted from the curves that bars reinforced with $0.5 \%$ MWCNT have lower strain, hence in terms have the higher modulus of elasticity. In this case; it can be seen, that the peak strain of bars with randomly distributed carbon fibers $(2.25 \%)$ and multiwalled carbon nano tubes $(0.5 \%)$ is higher than that of plain bars with about $44 \%$.

3.1. Tensile Modulus. Tensile modulus gives the measure of stiffness of the element, whenever the deflections are to restrict the higher modulus is required. The higher the tensile modulus, the lesser will be the deflection, that is, the element behavior is stiffer in that case. It was seen that tensile modulus of bars with random distribution of carbon fibers $(2.25 \%)$ was increased by $49.1 \%$ compared to plain bars. Tensile modulus of bars with random distribution of multiwalled carbon nanotubes $(0.5 \%)$ was increased by $70.9 \%$ compared to plain bars. Tensile modulus of bars with random distribution of CF $(2.25 \%)$ and MWCNT $(0.5 \%)$ was increased by $60 \%$ compared to plain bars. In the present case, higher tensile modulus was seen for the bars with random distribution of multiwalled carbon nanotubes

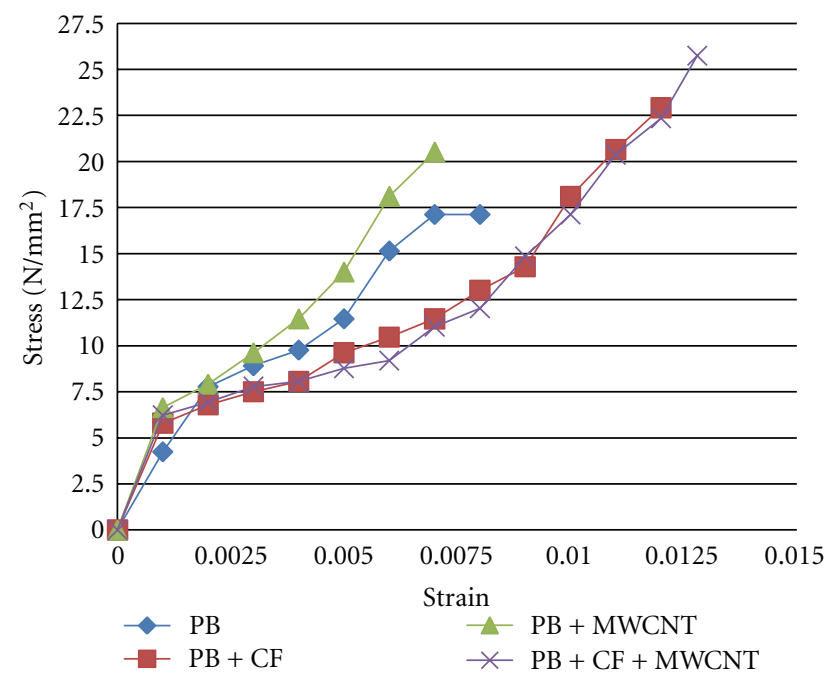

FIGURE 2: Stress-Strain behavior of various bars under Tensile loading.

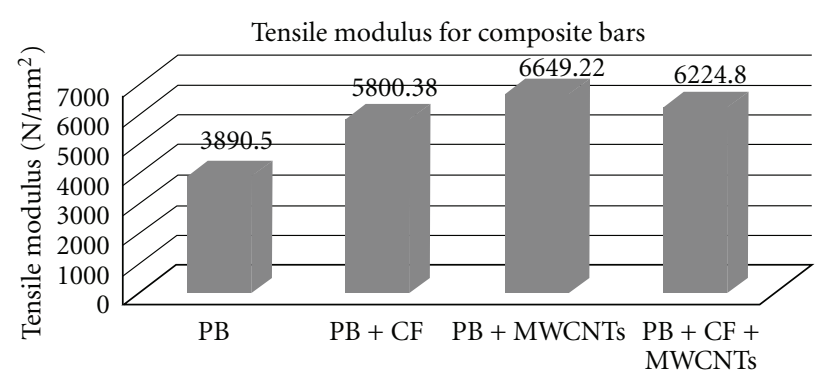

Figure 3: Variation of tensile modulus for all the bars.

(MWCNT 0.5\%), that is, $70.9 \%$ increase in the tensile modulus when compared to the plain bars. The graphical representation of tensile modulus is shown in Figure 3.

3.2. Deflection. Table 4 shows the variation of deflection for different proportions of the cement composite bars. The composite exhibits greater amount of deflections when compared to plain cement mortar bars (PBs) and plain cement mortar bars with carbon fiber reinforced bars (A). The composites have the ability to carry greater loads, as there is a need for greater amount of energy to produce the cracks. Crack bridging nature of carbon fibers and carbon nanotubes $(\mathrm{C})$ results in an increased load carrying capacity while undergoing greater amount of deflections. But there 


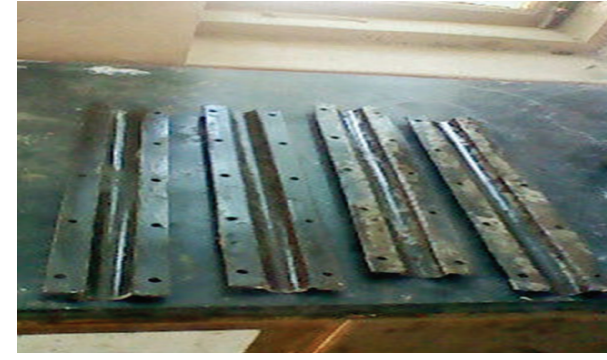

Figure 4: Moulds used for preparing round bars (half cell openable).

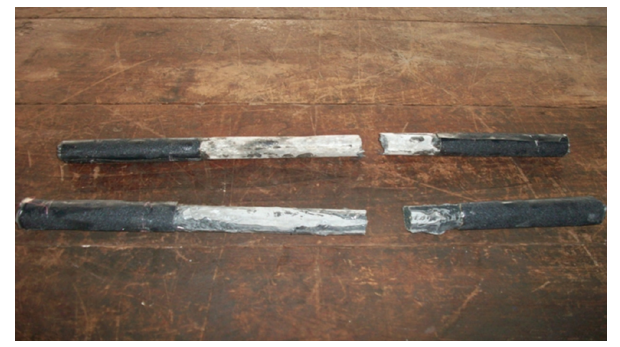

Figure 5: Failure pattern of the composite bar under tensile loading.

is a need for further study on this aspect as reported in the literature [4]. It has been reported that with the increase in MWCNT content, the Young's modulus of the composite will increase. This implies a greater stiffness of the material.

\section{Conclusions}

The study mainly focuses on the utilization of MWCNTs and CFs in cement-based matrix for direct tension tests leading to the development of a new material for structural applications. From the study, the following conclusions were drawn and are listed below.

(1) The results showed that there is a significant improvement in the load carrying capacity of the composite bars, compared to the plain bars (PBs). Plain Cement bars with $2.25 \%$ carbon fiber reinforcement (A) showed $38 \%$ increase in the ultimate load, where as plain cement bars with $2.25 \%$ carbon fibers and $0.5 \%$ MWCNT (C) showed 54\% increase in the load carrying capacity. Presence of both fibers, that is, carbon fiber and MWCNT has mainly contributed to the improvement of tensile load carrying capacity. Figure 5 shows the failure pattern of the composite bars under direct tensile loading.

(2) Calculated tensile modulus values indicate that the addition of CF and MWCNT (C) has increased the tensile modulus of the composite significantly. Tensile modulus values corresponding to the ultimate load and tensile modulus corresponding to initial slope of the stress strain curve showed an increasing trend. Bars with 0.5\% MWCNT (B) showed a maximum tensile modulus.

(3) Bars reinforced with randomly distributed carbon fiber $2.25 \%$ and multiwalled carbon nanotubes (C) $0.5 \%$ give higher tensile load carrying capacity.

(4) Ductile failure mode was observed in specimens; failure strain capacity of $44 \%$ higher was observed in bars with randomly distributed CF and MWCNT (C) as compared with plain bars (PB).

(5) Since the addition of nanotubes to the bars, that is, either reinforced to plain bars or reinforced along with carbon fibers to plain bars will increase tensile properties in terms of strength, strength to weight ratio. This proves their ability to become an ideal reinforcing material and it can be used for the construction of structures subjected to seismic, impact, dynamic, and so forth, loadings.

\section{References}

[1] P. K. Mehta and P. J. M. Monteiro, Concrete Microstructure, Properties, and Materials, Tata McGraw- Hill Edition, New Delhi, India, 2006.

[2] L. Y. Chan and B. Andrawes, "Finite element analysis of carbon nanotube/cement composite with degraded bond strength," Computational Materials Science, vol. 47, no. 4, pp. 994-1004, 2010.

[3] G. Zhi and Z. Gao, "Applications of nanotechnology and nanomaterials in construction," in Proceedings of the 1st International Conference on Construction in Developing Countries (ICCIDC-I '08), Advancing and Integrating Construction Education, Research \& Practice, Pakistan, Iran, 2008.

[4] J. M. Makar and G. W. Chan, "Growth of cement hydration products on single-walled carbon nanotubes," Journal of the American Ceramic Society, vol. 92, no. 6, pp. 1303-1310, 2009.

[5] A. Keyvani, "Huge opportunities for industry of nanofibrous concrete technology," International Journal of Nanoscience and Nanotechnology, vol. 3, no. 1, pp. 3-11, 2007.

[6] J. M. Makar and J. J. Beaudoin, "Carbon nanotubes and their applications in the construction industry," in Proceedings of the 1st International Symposium on Nanotechnology in Construction, pp. 331-341, Scotland, 2003.

[7] G. Srinivas, Characterization of the mechanical properties of carbon nanotube-based composites using the finite element method, M.S. thesis, Department of Mechanical Engineering, University of Cincinnati, New York, NY, USA, 2005.

[8] J. Makar, J. Margeson, and J. Luh, "Carbon nanotube/cement composites-early results and potential applications," in Proceedings of the 3rd International Conference on Construction Materials: Performance, Innovations and Structural Implications, Vancouver, pp. 1-10, British Columbia, Ottawa, Canada, 2005.

[9] P. Taylor, R. Krishna, B. Birgisson, and T. Cackler, "Workshop on nanotechnology for cement and concrete," in Proceedings of the National Concrete Pavement Technology Center and the National Science Foundation, pp. 1-60, Cooperation with the Nanoscale Science and Engineering and Technology Subcommittee, Arlington, Va, USA, 2007. 
[10] Z. S. Metaxa, M. S. Konsta-Gdoutos, and S. P. Shah, "Carbon nano reinforced concrete," ACI Special Publications Nanotechnology of Concrete: The Next Big Thing is Small SP, vol. 267, no. 2, pp. 11-20, 2009.

[11] S. P. Shah, M. S. Konsta-Gdouto, Z. S. Metaxa, and P. Mondol, "Nanoscale modfication of cementitious materials," Nanotechnology in Construction, pp. 125-130, 2009.

[12] A. K. Rana, S. B. Rana, A. Kumar, and V. Kiran, "Significance of nanotechnology in construction engineering," International Journal of Recent Trends in Engineering, vol. 1, no. 4, pp. 46-48, 2009.

[13] T. Nochaiya and A. Chaipanich, "Behavior of multi-walled carbon nanotubes on the porosity and microstructure of cement-based materials," Applied Surface Science, vol. 257, no. 6, pp. 1941-1945, 2011.

[14] J. S. Lawler, Hybrid fiber-reinforced in mortor and concrete, Ph.D. thesis, Northwestern University Evanston, Ill, IL, USA, 2001.

[15] J. S. Lawler, D. Zampini, and S. P. Shah, "Microfiber and macrofiber hybrid fiber-reinforced concrete," Journal of Materials in Civil Engineering, vol. 17, no. 5, pp. 595-604, 2005.

[16] P. Mondol, Nanomechanical properties Of Cementitious Materials, Ph.D. thesis, Northwestern University, 2008.

[17] Z. S. Metaxa, M. S. Konsta-Gdoutos, and S. P. Shah, "Mechanical properties and nanostructure of cement-based materials reinforced with carbon nanofibers and polyvinyl alcohol (PVA) microfibers," American Concrete Institute, ACI Special Publication, vol. 270, pp. 115-124, 2010.

[18] A. M. Hunashyal, S. J. Lohitha, S. S. Quadri, and N. R. Banapurmath, "Experimental investigation on effect of carbon nanotubes and carbon fibres on behaviour of plain cement composite beams," The IES Journal Part A: Civil and Structural Engineering, Taylor and Francis Publications, vol. 4, no. 1, pp. 29-36, 2011.

[19] G. T. Canebal, C. Dutta, V. Agrawal, and M. Rao, "Novel ultrasonic dispersion of carbon nanotubes," Journal of Minerals and Materials Characterization and Engineering, vol. 9, no. 3, pp. 165-181, 2010.

[20] M. S. Konsta-Gdoutos, Z. S. Metaxa, and S. P. Shah, "Highly dispersed carbon nanotube reinforced cement based materials," Cement and Concrete Research, vol. 40, no. 7, pp. 10521059, 2010.

[21] S. Musso, J. M. Tulliani, G. Ferro, and A. Tagliaferro, "Influence of carbon nanotubes structure on the mechanical behavior of cement composites," Composites Science and Technology, vol. 69, no. 11-12, pp. 1985-1990, 2009.

[22] M. S. Konsta-Gdoutos, Z. S. Metaxa, and S. P. Shah, "Nanoimaging of highly dispersed carbon nanotube reinforced cement based materials," in Proceedings of the 7th International RILEM Symposium on Fiber Reinforced Concrete Design and Applications RILEM Publications, R. Gettu, Ed., pp. 125-131, S.A.R.L., 2008. 

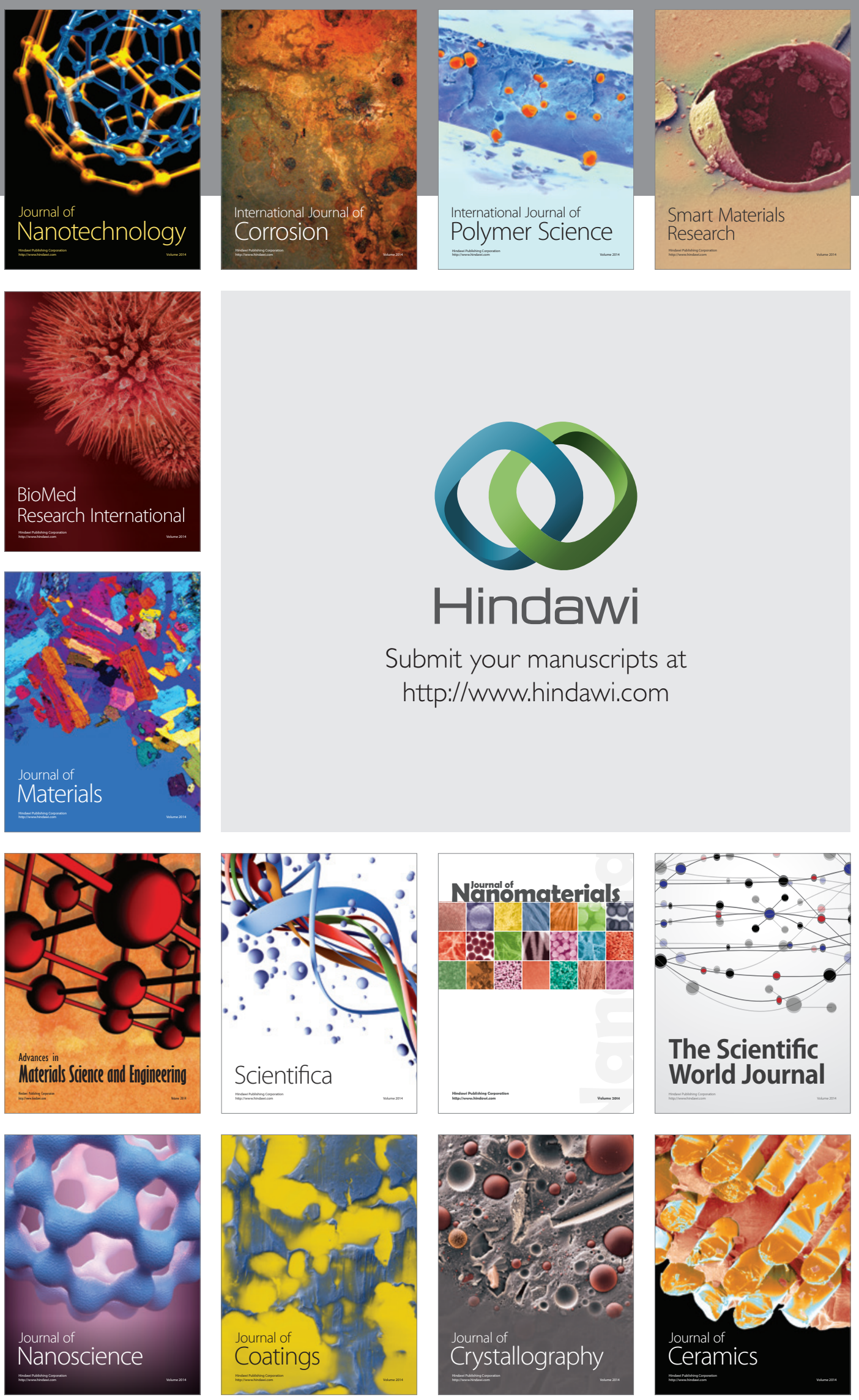

The Scientific World Journal

Submit your manuscripts at

http://www.hindawi.com

\section{World Journal}

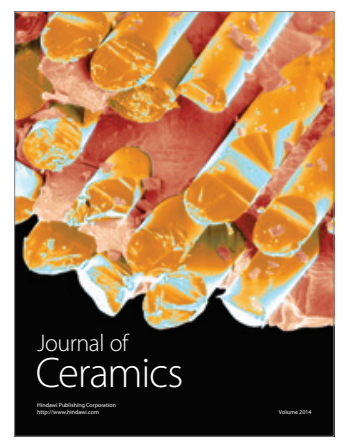

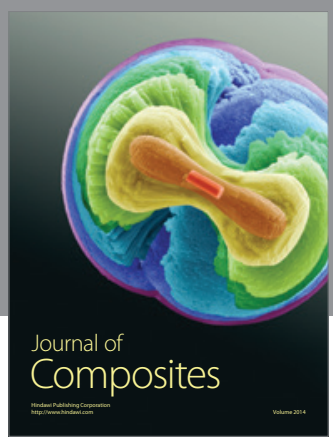
